REVIEW SERIES

\title{
Sleep - 9: An approach to treatment of obstructive sleep apnoea/hypopnoea syndrome including upper airway surgery
}

\section{F Ryan}

Thorax 2005;60:595-604. doi: 10.1136/thx.2004.036442

This article provides an overview of the management of the obstructive sleep apnoea/hypopnoea syndrome (OSAHS). Where possible, recommendations are based on a review of the relevant literature. With the exception of nasal continuous positive airway pressure, which is considered in greater detail elsewhere in the series, and certain oral appliances, the efficacy of many proposed treatments for OSAHS is not supported by data from randomised controlled clinical trials. To a considerable extent, treatment recommendations are based on data from uncontrolled studies, case series, consensus guidelines, practice parameters, and other less rigorous forms of evidence.

Correspondence to: Dr C F Ryan, Division of Respiratory Medicine, Department of Medicine, University of British Columbia, Vancouver, British Columbia, V5Z 3J5, Canada; fryan@ interchange.ubc.ca
$\mathrm{T}$ he indications for treating the obstructive sleep apnoea/hypopnoea syndrome (OSAHS) remain incompletely defined. A recent study showed a markedly increased incidence of cardiovascular disease (odds ratio $11.1 \quad$ (95\% confidence interval (CI) 3.9 to 32.3); $\mathrm{p}<0.001$ ) during a 7 year follow up period in previously healthy middle aged men with incompletely treated obstructive sleep apnoea (OSA). ${ }^{1}$ Much uncertainty still remains, however, regarding the natural history and consequences of untreated OSAHS. Until the results of further large scale epidemiological and natural history studies are available, it will remain unclear at which point on the continuum of sleep disordered breathing and its attendant physiological and psychosocial consequences the condition becomes clinically significant and merits treatment. Current treatment options vary markedly in their efficacy, degree of complexity, and potential for morbidity and adverse outcomes. The availability of diagnostic facilities and expertise in specialised treatments such as oral appliances and complex craniofacial surgery also varies considerably. Given these uncertainties, the treatment approach should be tailored to the individual patient based on a careful risk-benefit analysis that takes into account a variety of factors including:

- the reason for the patient's referral and his expectations of treatment;

- the severity of OSAHS in terms of the patient's symptoms, the presence of associated comorbidities, and the findings on overnight sleep monitoring;
- the presence of specific abnormalities of upper airway anatomy that may be amenable to surgical treatment;

- the local expertise in terms of specialised treatments; and

- the ability to provide long term follow up.

\section{ASSESSMENT OF THE PATIENT}

The initial assessment of a patient with suspected OSAHS includes a detailed history and physical examination with a particular emphasis on sleep related symptoms, cardiorespiratory disease, endocrine/metabolic disorders, and abnormalities of upper airway structure and function that predispose to upper airway obstruction during sleep. Information from the history, physical examination, and overnight sleep monitoring is essential in guiding therapeutic decisions. The history reveals the subjective severity of the patient's symptoms, especially daytime hypersomnolence. The Epworth Sleepiness Scale $^{2}$ provides a semiquantitative measure of sleepiness that correlates with apnoea severity, but may miss the not uncommon complaints of fatigue and tiredness. Collateral history from the bed partner expressing concerns about snoring, witnessed apnoeas, and impaired functioning is often the main motivation for the patient's attendance. It is important, however, that treatment is not solely undertaken to resolve the bed partner's complaints. Modifiable risk factors including recent weight gain, alcohol use (especially close to bedtime), sedative/hypnotic use, cigarette smoking, and chronic nasal obstruction should be routinely sought. The general appearance of the patient may prompt specific questions relating to treatable endocrine disorders such as hypothyroidism, acromegaly or Cushing's syndrome. Rarely, neurological symptoms will provide clues to the presence of generalised neuromuscular weakness or a central nervous system disorder such as the Arnold-Chiari malformation that may give rise to sleep disordered breathing. ${ }^{3}$

It is important to question the patient about co-morbid medical conditions including systemic hypertension, atherosclerotic disease, heart failure, chronic lung disease, and neuromuscular disease that may be worsened by OSAHS and that should lower the threshold for instituting specific treatment. Co-morbid conditions may also influence the choice of treatment for OSAHS. For example, nasal continuous positive airway pressure (CPAP) is likely to be a better 
option than upper airway surgery for patients with co-morbid medical conditions.

The physical examination is often superficially unremarkable in patients with OSAHS, except for the common findings of obesity and systemic hypertension. A focused examination of the upper airway, however, will usually reveal evidence of craniofacial soft tissue and skeletal abnormalities that predispose to upper airway narrowing. Various simple measurements ${ }^{4}$ such as increased neck circumference, decreased thyro-mental distance, steep thyro-mental plane, and high Mallampati oropharyngeal score reflect regional neck adiposity, mandibular deficiency, and crowding of the posterior oropharynx that may contribute to upper airway obstruction during sleep. Enlarged tonsils are readily apparent. Nasal obstruction can be identified by speculum examination, but more detailed otorhinolaryngological assessment may be required to identify specific anatomical abnormalities such as a deviated nasal septum, nasal polyposis, enlarged adenoids, and upper airway tumours.

Certain physical factors may prevent the use of specific treatment options. Severe nasal obstruction may preclude nasal CPAP or oral appliance therapy and may need to be addressed before these treatments are considered. Most oral appliances require adequate dentition for their effective use. Temporomandiublar joint dysfunction may prevent the use of an oral appliance. Upper airway surgery may not be a suitable option for patients who use their voice professionally.

\section{CONSERVATIVE TREATMENT Lifestyle modification}

In a recent systematic review which identified 316 articles, there were no randomised trial data upon which to base a conclusion that simple non-invasive lifestyle changes improve OSAHS. ${ }^{5}$ Nevertheless, common sense dictates the importance of identifying and attempting to correct lifestyle issues that may be contributing to the development or worsening of OSAHS. These lifestyle issues also contribute to co-morbid conditions that may be adversely impacted by untreated OSAHS. The term "syndrome Z" has been coined to highlight the potential interaction between OSAHS and various risk factors for cardiovascular disease. ${ }^{6}$

\section{Weight reduction}

About two thirds of patients with OSAHS are obese $(>120 \%$ ideal body weight). ${ }^{7}$ Obesity, particularly regional neck obesity, ${ }^{8-11}$ is a major risk factors for OSAHS. Changes in body weight are frequently associated with pronounced changes in the severity of OSAHS. ${ }^{12-14}$ The relationship between the degree of obesity and the severity of OSAHS is non-linear, ${ }^{12}$ however, making it difficult to prescribe precise weight reduction goals for individual patients. Although the mechanisms whereby weight gain causes OSAHS have not been fully defined, it is probable that regional adiposity in the neck alters the pressure-area relationship of the pharynx and results in a reduction in transmural pressure favouring pharyngeal occlusion during sleep. ${ }^{15}$ Obesity interacts with other risk factors such as craniofacial structure, ${ }^{16}$ such that in many patients, even mild to moderate obesity may precipitate OSAHS. ${ }^{17}$ In a survey using anthropometric measures, chart reviews, written questionnaires and interviews in 49 men with newly diagnosed OSAHS, we found that $84 \%$ reported a mean (SD) weight gain of 17 (15) kg since the onset of their symptoms (mean (SD) 5 (5) years). ${ }^{18}$ Weight gain was associated with binge eating and depression. Most attributed their weight gain to overeating and/or reduced physical activity. Of the patients who attempted weight loss, 95\% regained all or more of their weight.

In a critical review of weight loss as a treatment for OSAHS, Strobel and Rose ${ }^{19}$ observed that most studies suffered from methodological limitations including lack of random assignment to treatment groups, confounding of treatment interventions, absence of untreated controls, and lack of adequate follow up assessment. A variety of weight loss interventions including dietary weight loss, very low calorie diets, cognitive behavioral therapy, anorexiant drugs, and bariatric surgery were associated with weight reductions ranging from $5 \%$ to $50 \%$. In general, bariatric surgery resulted in more impressive weight reduction than medical treatment. Dramatic reductions in the apnoea/hypopnoea index (AHI) were seen in some patients, together with improvements in oxygenation, sleep architecture, blood pressure, self-reported daytime alertness, multiple sleep latency scores, and physiological measures of upper airway collapsibility. Data on long term follow up were absent from most studies and, when provided, indicated that weight loss was not maintained 2 years after treatment. These results mirror the experience in other obese individuals for whom long term maintenance of weight loss is difficult, if not impossible, to achieve. Limited data were provided about postoperative complications following bariatric surgery, although some deaths were reported. Also, the potential medical risks associated with recurring weight loss and weight gain have not been adequately addressed.

Faced with these uncertainties about the role of weight reduction and its long term efficacy in the treatment of OSAHS, what advice should the clinician give? Certainly, all obese patients with OSAHS should be informed that obesity is likely to be a major contributory factor to their sleep disordered breathing. They should be counselled to lose weight if possible, regardless of what other treatments are undertaken. Weight reduction and other lifestyle adjustments may be the appropriate primary treatment strategy for patients with mild OSAHS who are not sleepy and have no serious co-morbidities. These patients should be followed closely, however, to ensure that their target weight reduction is achieved, and that the desired improvement in their OSAHS is obtained. Some specific therapies such as oral appliances and palatal surgery may provide only a marginal therapeutic benefit in individual patients that is easily eliminated by even modest weight gain. Weight reduction and avoidance of weight gain are important adjunctive strategies for these patients. Weight reduction may lower the effective nasal CPAP pressure required to control OSAHS and thereby potentially improve compliance. Some patients are motivated by the prospect that significant weight reduction may allow them eventually to be free of nasal CPAP therapy. An aggressive approach to weight reduction using very low calorie diets or bariatric surgery may be appropriate for some morbidly obese patients with severe OSAHS, particularly if undertaken as part of a comprehensive treatment programme. This approach may also be justified for patients with severe OSAHS who cannot tolerate nasal CPAP therapy and are unsuitable for tracheostomy. Finally, the potentially favourable impact of weight reduction on comorbid conditions such as hypertension, heart failure, respiratory failure, insulin resistance and dyslipidaemia, and their interactions with OSAHS, should be impressed upon the patient. ${ }^{6}$

\section{Avoidance of alcohol and other respiratory depressants}

Alcohol selectively suppresses upper airway dilator muscle activity while leaving the diaphragm virtually unaffected..$^{20}$ This effect increases inspiratory resistance during wakefulness and sleep ${ }^{22}$ and predisposes to obstructive sleep apnoea. Alcohol increases the frequency of apnoeas and hypopnoeas during sleep in normal subjects and patients with OSAHS, even in low doses. ${ }^{23}$ At higher doses the duration of apnoeas 
and the severity of associated hypoxaemia is increased. ${ }^{24} 25$ Similar effects may be seen with other respiratory depressants such as benzodiazepines, ${ }^{26}$ narcotics ${ }_{,}{ }^{27}$ and barbiturates. Arousal responses to hypercapnia and hypoxia may also be blunted by respiratory depressants. Patients with OSAHS should therefore be counselled to avoid alcohol and sedativehypnotic medications. Where such medications cannot be easily discontinued, nasal CPAP therapy should be recommended to control the OSAHS. Patients who are unwilling to avoid alcohol completely should be advised not to drink within 3-4 hours of retiring to bed. ${ }^{28}$

\section{Smoking cessation}

Cigarette smoking is a risk factor for snoring ${ }^{29}$ and OSAHS. ${ }^{30}$ Data from 811 adults enrolled in the University of Wisconsin Sleep Cohort Study were analysed using logistic regression with control for potential confounders. ${ }^{30}$ Compared with never smokers, current smokers had a significantly greater risk of sleep disordered breathing (odds ratio 4.44), with heavy smokers ( $\geqslant 40$ cigarettes/day) being at the greatest risk. Former smokers were not at increased risk. The mechanism of this interaction is unclear but may relate to increased upstream inspiratory upper airway resistance as a consequence of nasal mucosal inflammation. Patients with OSAHS who are current cigarette smokers should be counselled to quit. They should also be warned about the potential for weight gain associated with quitting cigarette smoking.

\section{Sleep hygiene}

Sleep deprivation reduces ventilatory responses to hypoxia and hypercapnia ${ }^{31-33}$ and selectively decreases upper airway muscle activity in normal subjects. ${ }^{34}$ Sleep deprivation increases the number of apnoeas in snorers and patients with mild OSAHS. ${ }^{31}{ }^{34}$ Short term sleep fragmentation does not appear to affect ventilatory responses to hypercapnia ${ }^{35}$ but does increase upper airway collapsibility to a greater extent than sleep deprivation. ${ }^{36}$ Thus, sleep fragmentation and sleep deprivation as a consequence of poor sleep hygiene could exacerbate OSAHS. In the absence of evidence from controlled trials, it is reasonable to advise patients of the possible interaction between poor sleep hygiene and OSAHS. Measures to improve sleep hygiene should be advocated, including avoidance of caffeine and other stimulants, a regular sleep-wake schedule, environmental measures to promote a comfortable undisturbed sleep, and avoidance of daytime napping. The potential impact on sleep disordered breathing of other sleep disorders that cause sleep fragmentation, such as periodic limb movement disorder, should also be considered.

\section{Sleep position}

The collapsibility of the upper airway during sleep in patients with OSAHS, as measured by the critical closing pressure (Pcrit), ${ }^{37}$ is lower in the lateral than in the supine sleep position. ${ }^{38}$ In a retrospective study of 574 patients with OSAHS, Oksenberg and colleagues found that $56 \%$ had positional apnoea as defined by a supine AHI $\geqslant 2$ times higher than lateral AHI. ${ }^{39}$ These patients were younger, less obese, had less severe OSAHS, and were less sleepy. The severity of apnoeas as measured by duration, degree of oxygen desaturation, and change in heart rate is greater in the supine position than in the lateral sleep position. ${ }^{40}$ Obese patients are less likely to show a reduction in AHI in the lateral position than in the supine sleep position. ${ }^{41}$ The effect on systemic blood pressure of promoting the lateral sleep position for 1 month was studied in 13 patients with OSAHS, six of whom were hypertensive. ${ }^{42}$ Mean 24 hour, awake and sleeping blood pressure fell significantly (systolic/diastolic $6.4 / 2.9,6.6 / 3.3,6.5 / 2.7 \mathrm{~mm} \mathrm{Hg}$, respectively). The reduction in systolic blood pressure was greater in the hypertensive patients than in those who were normotensive. Jocik and coworkers compared nasal CPAP with positional treatment in 13 patients with positional OSAHS using a prospective, randomised, single blind, crossover study design. ${ }^{43}$ Positional treatment was highly effective in reducing supine sleep (median 0; range 0-32 minutes). Although AHI was lower and minimum oxygen was higher with nasal CPAP, there was no difference between the two treatments in the main outcome measures of sleep architecture, daytime sleepiness, psychometric test performance, mood, and quality of life. Taken together, these data suggest that promoting the lateral sleep position is a worthwhile goal that may be applicable to the majority of patients with OSAHS. Various devices that incorporate a soft ball or sock attached to the back of the pyjamas have been tried. While this technique is effective in the short term, its practicality and efficacy in the long term have not been tested. Positional treatment should be considered for patients with mild OSAHS and as an adjunctive measure for patients receiving other treatment such as nasal CPAP or an oral appliance.

\section{Relief of nasal obstruction}

Chronic nasal obstruction is a common complaint among patients with OSAHS and can compromise its management. Nasal obstruction due to anatomical abnormalities or nasal mucosal congestion can increase upstream inspiratory resistance, promoting more negative intraluminal pressure in the pharynx and predisposing to pharyngeal occlusion during sleep. Nasal obstruction has been shown to increase the number of apnoeas and hypopnoeas and to cause sleep fragmentation. ${ }^{44-47}$ However, treatment of nasal obstruction with decongestants or surgery does not appear to improve OSAHS. ${ }^{48-51}$ The reasons for this lack of efficacy are unclear. Series $e t$ al $^{48}$ observed an improvement in OSAHS following nasal surgery in a subgroup of patients who did not have cephalometric abnormalities commonly found in OSAHS such as an inferiorly positioned hyoid bone and a narrow oropharyngeal anteroposterior dimension. This suggests that the failure of measures that relieve nasal obstruction to reduce OSAHS may be related to the persistence of anatomical abnormalities in the pharynx. Nevertheless, the absence of improvement in OSAHS following treatment of nasal obstruction in unselected patients should not deter consideration of this treatment option. In selected patients, specific abnormalities such as a grossly deviated nasal septum or nasal polyposis may warrant referral to an otorhinolaryngologist for consideration of surgical treatment options. Furthermore, severe nasal mucosal congestion may impede nasal CPAP therapy or oral appliance therapy and should be addressed to enhance the efficacy of these treatments. Measures to relieve nasal congestion include nasal corticosteroids, oral non-sedating antihistamines, and various surgical procedures such as cauterisation of the nasal turbinates, polypectomy, submucosal resection, turbinectomy, and nasal septoplasty.

\section{Pharmacological treatment}

The limitations of existing treatments for OSAHS have led to continued interest in drug therapy as a potential alternative approach. A wide variety of pharmacological agents have been tested. Putative mechanisms of action include increased ventilatory drive (medroxyprogesterone, acetazolamide, theophylline, doxapram, naloxone, nicotine, carbon dioxide); suppression of REM sleep (protriptyline, clonidine, selective serotonin reuptake inhibitors); decreased sympathetic tone and baroreceptor activity (metoprolol, alazapril); stabilisation of ventilation (sabeluzole); and selective activation of upper airway dilator muscles (strychnine, paroxetine, trazodone and L-tryptophan). Many of these agents are limited by poor 
patient tolerance and their use is not supported by randomised controlled trials. Two recent reviews have summarised the role of pharmacotherapy in OSAHS and highlighted the paucity of well designed randomised controlled trials in this area. ${ }^{52} 53$

In a randomised, double blind, placebo controlled, crossover study in 10 men with OSAHS, four of whom were hypercapnic, Cook et al ${ }^{54}$ found that medroxyprogesterone $150 \mathrm{mg} /$ day had no effect on AHI or total sleep time. Whyte et $a l^{55}$ compared acetazolamide, protriptyline and placebo in eight men and two women with OSAHS (AHI >15/hour) using a randomised, double blind, crossover design. Acetazolamide $250 \mathrm{mg}$ qid for 14 days reduced the AHI $(p<0.03)$ but not the frequency of arousals or subjective daytime sleepiness. Long term use was limited by intolerable side effects, particularly parasthaesiae. Protriptyline had no beneficial affect on AHI or symptoms. In two other randomised, double blind, crossover studies, protriptyline showed improvements in subjective daytime sleepiness but no change in AHI compared with placebo. ${ }^{56}{ }^{57}$ Mulloy and coworkers studied the effect of theophylline in 12 men with OSAHS in a randomised, double blind, placebo controlled, crossover study. ${ }^{58}$ The AHI decreased from a mean (SD) of 49 (9)/hour to $40(9) /$ hour ( $p=0.02)$, but total sleep time, sleep efficiency and sleep architecture deteriorated. Randomised, blinded, placebo controlled, crossover studies of aminophylline, buspirone, sabeluzole and clonidine have failed to demonstrate any benefit of these agents in OSAHS.

In summary, the currently available evidence does not support the use of pharmacological agents in the treatment of OSAHS. The future development of new pharmacological approaches to OSAHS awaits a greater understanding of the central neuronal mechanisms and the various neurotransmitters involved in the modulation of motor output to the upper airway muscles. This is currently an area of active research. ${ }^{59}{ }^{60}$ Finally, two recent randomised, double blind, placebo controlled trials of modafinil in patients with OSAHS who had residual sleepiness despite nasal CPAP therapy showed significant improvement in alertness ${ }^{61}$ and subjective and objective daytime sleepiness, ${ }^{62}$ suggesting that this agent may have a role as adjunctive symptomatic therapy.

\section{Oxygen}

Supplemental oxygen is an accepted treatment for patients with chronic lung disease who have significant arterial oxygen desaturation during sleep. Arterial oxygen desaturation is a common pathophysiological consequence of OSAHS that may contribute to the development of complications such as pulmonary hypertension, cardiac dysrhythmias, and cognitive impairment. ${ }^{63-66}$ Relief of hypoxaemia is therefore an important outcome measure of successful treatment of sleep disordered breathing. Supplemental oxygen improves overall oxygenation during sleep in patients with OSAHS but increases apnoea duration while reducing apnoea frequency only slightly. ${ }^{67}{ }^{68}$ Daytime sleepiness is not reduced. In most instances supplemental oxygen is insufficient as sole therapy for OSAHS. Occasionally, patients with co-morbid medical conditions such as chronic heart or lung disease who have significant oxygen desaturation in association with otherwise mild asymptomatic sleep disordered breathing can be considered for supplemental oxygen alone. In these patients consideration should also be given to a trial of nasal CPAP therapy. Oxygen is also indicated as adjunctive therapy for patients using positive airway pressure devices for OSAHS who have persistent arterial oxygen desaturation at the highest tolerated pressures.

\section{Miscellaneous devices and aids}

Various interventions have been tested to explore the pathophysiological mechanisms of upper airway obstruction during sleep in OSAHS. Some pilot studies have been reported, but none of these interventions has been evaluated by large scale controlled trials. They include neck collars, ${ }^{69}$ nasal valve dilators, ${ }^{70}$ nasopharyngeal tubes, ${ }^{71}$ pharyngeal lubricant, ${ }^{72}$ electrical stimulation of upper airway dilator muscles, ${ }^{73}$ transtracheal air insufflation, ${ }^{74}$ and even atrial pacing. ${ }^{75}$ Although modest efficacy has been claimed for some of these approaches, their widespread use is likely to be limited by discomfort, impracticality, or the potential for serious complications. A recent report of the Clinical Practice Review Committee of the American Academy of Sleep Medicine noted that the paucity and limited quality of scientific data on non-prescription treatments for OSAHS resulted in insufficient information upon which to base standards of practice recommendations. ${ }^{76}$

\section{UPPER AIRWAY SURGERY \\ Rationale}

Surgical treatment of OSAHS predated the development of nasal CPAP and oral appliances. ${ }^{77} 78$ The aim of surgical treatment is to bypass or remove the site of upper airway obstruction. Tracheostomy achieves this goal by creating an artificial airway distal to the collapsing segment of the pharynx and bypassing the site of upper airway obstruction. Tracheostomy, which remains the only treatment for OSAHS that is consistently effective, retains an important role in the management of the occasional patient with severe life threatening OSAHS for whom nasal CPAP therapy is not an option. The disfiguring nature and the attendant long term morbidity of tracheostomy have led to the development of other treatments including a number of alternative surgical approaches. These procedures seek to remove the site of upper airway obstruction by either increasing the calibre or reducing the collapsibility of the airway through a variety of mechanisms including:

- resection of redundant soft tissue (nasal surgery, uvulopalatopharyngoplasty, laser assisted uvulopalatoplasty, midline glossectomy);

- induction of scar tissue formation (cautery or radiofrequency ablation of soft palate, tongue or epiglottis); or

- displacement of bony and ligamentous attachments of upper airway soft tissue structures (maxillary and mandibular osteotomies, tongue and hyoid suspensions).

\section{Evidence}

The introduction of new surgical procedures into clinical practice without rigorous evaluation is commonplace ${ }^{79}$ and upper airway surgery for OSAHS is no exception. Bridgman and colleagues ${ }^{80}$ recently reported a detailed review of the literature on surgery for OSAHS through the Cochrane Airways Group Sleep Apnoea Randomised Controlled Trial Register. Their literature search was expanded to include Medline, the reference lists of relevant review articles, the databases of several other agencies, and discussions with experts in the field. Among 656 articles assessed, no randomised or quasi-randomised trials were identified comparing any surgical intervention with another surgical or non-surgical intervention for OSAHS. The American Sleep Disorders Association issued practice parameters for the surgical treatment of OSAHS ${ }^{81}$ based on an extensive review of the literature between 1966 and $1995 .{ }^{82}$ In the absence of any randomised trials, their recommendations were based entirely on Sackett's grade C, level III or V evidence consisting of non-randomised concurrent cohort studies and case series. ${ }^{83}$ Consequently, any recommendations regarding the role of upper airway surgery in the treatment of OSAHS must take into account the weakness of the 
existing data. Nevertheless, considerable clinical experience with these various techniques has enabled the elucidation of a pragmatic approach to the principles of surgical treatment for OSAHS.

\section{Treatment principles}

For the fewer than $1 \%$ of patients who have a specific anatomical upper airway lesion such as adenotonsillar enlargement, antrochoanal polyp, or tumour as the cause of OSAHS, ${ }^{84}{ }^{85}$ surgical resection is probably the treatment of choice. Most patients, however, have a dynamic upper airway obstruction occurring at the level of the velopharynx behind the soft palate. ${ }^{86}$ Some have additional loci of obstruction occurring more caudally in the retroglossal oropharynx or hypopharynx, or may obstruct predominantly in these regions. ${ }^{86}{ }^{87}$ Various surgical procedures have been developed to target these areas of obstruction. Since surgical success is believed to depend on selecting a procedure that targets the specific area of abnormality, ${ }^{88}{ }^{89}$ it is important to map the site(s) of upper airway obstruction carefully before surgery. A number of imaging and laboratory modalities have been used for this purpose including cephalometry, ${ }^{90}$ CT scanning, ${ }^{91}$ nasopharyngoscopy awake ${ }^{92}$ and asleep, ${ }^{89}$ and measurements of regional pharyngeal pressure, flow and resistance. ${ }^{86}$ Because upper airway surgery is invasive, a phased approach is recommended beginning with less radical procedures and advancing to more aggressive interventions when initial treatment responses are inadequate. Upper airway surgery is largely irreversible, so the aim of treatment is to achieve cure, or at least equivalent efficacy to nasal CPAP, the currently accepted standard treatment. Objective measurement of the severity of OSAHS preoperatively and the postoperative response to treatment is essential. Ongoing follow up of patients who undergo corrective upper airway surgery for OSAHS is strongly recommended because the long term efficacy of these procedures has not been well established. Some forms of upper airway surgery may provide only marginal therapeutic benefit that is easily erased by weight gain or the passage of time (box 1).

\section{Surgical procedures}

\section{Adenotonsillectomy}

Hypertrophy of the tonsils and adenoids is a common cause of OSAHS in children. Adenotonsillectomy is curative in 75$100 \%$ of children with OSAHS, including those who are obese. ${ }^{93}$ Severe preoperative OSAHS and persistent snoring postoperatively are risk factors for persistent OSAHS and should prompt a repeat assessment. In adults, adenotonsillar enlargement is occasionally the major cause of OSAHS. Verse and associates $^{94}$ studied nine patients prospectively who underwent tonsillectomy as the sole treatment for OSAHS. Eight had a good response as measured by a reduction in AHI of $\geqslant 50 \%$ or to $<20 /$ hour postoperatively.

\section{Uvulopalatopharyngoplasty (UPPP)}

Uvulopalatopharyngoplasty (UPPP) is a procedure that attempts to enlarge the retropalatal airway by excising the tonsils along with portions of the anterior and posterior tonsillar pillars and the free margin of the soft palate including the uvula, while preserving the function of the proximal palatal musculature. It was first introduced by Fujita $^{95}$ in 1981 and since then has been widely used for the treatment of OSAHS. A meta-analysis of 37 papers published between 1966 and 1995 was performed by Sher and associates. ${ }^{82}$ UPPP resulted in significant reductions in the severity of OSAHS as measured by a decrease in the respiratory disturbance index (RDI) of $38 \%$ weighted average (range $-72 \%$ to $+12 \%$ ). A higher baseline severity of OSAHS was associated with less improvement after UPPP. A good response to UPPP, as defined by a $50 \%$ decrease in RDI and a
Box 1 Obstructive sleep apnoea/hypopnoea

syndrome: upper airway surgery

Surgical treatment principles

- For specific anatomical obstructing lesions surgery is the treatment of choice (e.g. adenotonsillectomy).

- Preoperative mapping of the locus of upper airway obstruction is essential.

- The invasive nature of surgical treatment dictates a phased approach progressing from less to more radical procedures

- Irreversibility of surgery dictates that the treatment goal is cure or efficacy equivalent to nasal CPAP therapy.

- Objective assessment of the severity of OSAHS before and after surgery is essential.

- Long term follow up is strongly recommended because of the high rates of treatment failure.

Surgical procedures

- Adenotonsillectomy: curative in children and selected adults.

- Uvulopalatopharyngoplasty (UPPP): for obstruction confined to the velopharynx.

- Laser assisted uvulopalatoplasty: not indicated for OSAHS.

- Other palatal procedures: not indicated for OSAHS.

- Maxillomandibular advancement: should be restricted to specialised centres.

- Tongue base surgery: possible role for temperature controlled radiofrequency tissue ablation in mild to moderate OSAHS.

- Tracheostomy: emergency management of severe OSAHS when nasal CPAP therapy is not an option.

postoperative apnoea index of $<10$ and RDI $<20$, was obtained in $41 \%$ of patients. Although no validated universally accepted clinical method of determining the site of upper airway narrowing or collapse in OSAHS has been developed, the results of pooled data from several studies using a variety of techniques indicate that obstruction occurring distal to the velopharynx portends a poor outcome following UPPP. Only 5\% of such patients obtained a good response. Even among patients who were obstructed exclusively at the level of the velopharynx, only $52 \%$ had a good response. The good responders had a lower mean RDI than the poor responders (RDI 30/hour $v$ 56/hour). Data on long term follow up after UPPP are limited. Larsson and colleagues $^{96}$ followed a group of 50 patients for a mean of 46 months (range 34-78) after UPPP. Response rates fell from $60 \%$ at 6 months to $30 \%$ at 21 months in association with significant weight gain. Complication rates are difficult to define from the literature. Postoperative pain is common but self-limited. Some degree of velopharyngeal insufficiency may occur in up to $40 \%$ of patients. ${ }^{97}$ Postoperative upper airway obstruction has been reported in $10 \%$ of patients and deaths have occurred. ${ }^{98}$ Velopharygeal stenosis has also been reported and may explain worsening OSAHS in some patients following UPPP.

The reasons for the overall poor success rate of UPPP are unclear. The $95 \%$ failure rate among patients with upper airway obstruction caudal to the velopharynx suggests that persistent obstruction at this level is responsible; but only $50 \%$ of patients with exclusively velopharyngeal obstruction 
obtain a good response. Langin and co-workers ${ }^{99}$ recently studied 20 patients using cephalometry and CT scanning of the upper airway before and after UPPP. Seven patients (35\%) had a good response. Good responders had an increase in the cross-sectional area of the retropalatal oropharynx following UPPP whereas poor responders did not. The crosssectional area of the velopharynx after UPPP was larger in good responders than in poor responders. The change in the size of the narrowest segment of the oropharynx correlated with the change in the AHI $(\mathrm{p}<0.02)$. These results suggest that failure to increase the calibre of the velopharynx may be an additional reason for failure to achieve a good response to UPPP. The long term efficacy of UPPP is often attenuated by weight gain, suggesting that it is a marginal treatment the efficacy of which can easily be abolished by changes in other factors that influence the collapsibility of the upper airway.

Laser assisted uvulopalatoplasty

Laser assisted uvulopalatoplasty (LAUP) is a modification of the UPPP procedure that results in a less radical resection of palatal tissue. A carbon dioxide laser is employed to vaporise the uvula and free margin of the soft palate. LAUP is performed as a one stage or multi stage procedure under local anaesthetic in the surgeon's office. ${ }^{100}$ Originally introduced for the treatment of snoring, ${ }^{101}$ LAUP increasingly gained popularity in the treatment of patients with OSAHS. An editorial in Thorax drew attention to the weak evidence and the overall limited efficacy of LAUP in the treatment of OSAHS. ${ }^{102}$ Subsequently, Littner et al ${ }^{103}$ conducted a Medline literature search covering the period up to September 2000 that yielded six case series and one retrospective cohort study containing analysable data. A meta-analysis of these studies revealed an average adjusted effects size of 0.251 , indicating a small reduction in AHI following LAUP. Using similar criteria to those outlined earlier for UPPP, good response rates of 27$41 \%$ were observed; $20-30 \%$ of patients were objectively worse following LAUP. This may be related to reduced velopharyngeal cross-sectional area caused by palatal fibrosis as a consequence of the LAUP procedure. ${ }^{104-106}$ In the only randomised controlled trial to date, Ferguson and colleagues studied 45 patients with mild OSAHS (AHI 10-27/hour) who were assigned to either LAUP or no treatment. ${ }^{107}$ The AHI was reduced by $21 \%$ overall in the LAUP treated group compared with no change in the control group. Less than a quarter of the LAUP treated patients had a good response in terms of a reduction in AHI to less than 10/hour and a satisfactory improvement in symptoms. Despite this limited efficacy, roughly half of the patients were satisfied with the LAUP treatment. The long term results of LAUP have not been defined but there are some data to suggest that short term improvements are not maintained over time. ${ }^{106}$ Adverse effects include postoperative pain, velopharyngeal insufficiency, dysphagia, and a sensation of dry throat. The development of postoperative upper airway oedema and narrowing has raised concerns about the advisability of performing LAUP as an outpatient procedure for OSAHS. ${ }^{108}$ Practice parameters issued by the Standards of Practice Committee of the American Academy of Sleep Medicine advise that LAUP is not recommended for the treatment of sleep related breathing disorders. ${ }^{103}$

\section{Other palatal procedures}

Various other procedures designed to stiffen or ablate palatal tissue have been described including laser palatoplasty ${ }^{109}$ using a neodymium:yttrium aluminum-garnet laser, cautery assisted palatal stiffening, ${ }^{110}$ and radiofrequency ablation. ${ }^{111}$ These procedures are intended for the treatment of snoring and are not indicated for the treatment of OSAHS.
Maxillary, mandibular, and hyoid advancement

The limited efficacy of UPPP prompted the development of surgical procedures directed at relieving upper airway compromise distal to the velopharynx in the retroglossal oropharynx and hypopharynx. These procedures-which include inferior sagittal mandibular osteotomy with genioglossus advancement, hyoid myotomy and hyothyroidopexy; total subapical mandibular osteotomy; bilateral sagittal split mandibular osteotomy; and LeFort 1 maxillary osteotomyare performed in various combinations and are designed to advance the ventral wall of the pharynx. Maxillary advancement appears to facilitate a greater degree of mandibular advancement and, in addition, may increase the calibre of the velopharynx. Coordination of care between surgeon and orthodontist is important to ensure satisfactory dental occlusion postoperatively. It is generally accepted that the choice of surgical intervention should be based on the location of upper airway compromise as determined by such procedures as lateral cephalometry and fibreoptic nasopharyngoscopy. A staged surgical approach has been advocated to avoid the more invasive and complex procedures where possible, but there is not general agreement on the necessity of this strategy. Riley et al ${ }^{12}$ reported the results of a two phase surgical approach in 306 patients. Fibreoptic endoscopy and lateral cephalometry were used to classify the sites of upper airway compromise into type I (retropalatal), type II (retropalatal and retrolingual), and type III (retrolingual) obstruction, respectively. Stage I procedures included UPPP for retropalatal narrowing and inferior sagittal mandibular osteotomy with genioglossus advancement and hyoid myotomy and suspension for retroglossal obstruction. Patients who failed to respond adequately to stage I procedures, as determined by polysomnography at least 6 months postoperatively, were offered the stage II procedure consisting of maxillomandibular advancement. Other groups have employed maxillomandibular and hyoid advancement as the primary surgical approach. ${ }^{113-115}$ Interpretation and comparison of the results of these studies is problematic because of considerable heterogeneity within and between studies in the patient selection criteria, previous or concomitant surgical procedures, polysomnographic techniques, confounding variables such as postoperative weight loss, and definitions of a good response. Good response rates to stage I surgical procedures ranged between $23 \%$ and $67 \%$. Stage II procedures yielded good response rates of $75-100 \%$ whether as primary treatment or following stage I surgery. ${ }^{112-116}$ The more recent results suggest that the staged approach may not be warranted, with some investigators advocating that maxillomandibular advancement be performed as the primary surgical treatment. It remains unclear which patients are most suitable for this treatment approach. Limited long term follow up data suggest that good response rates of $80 \%$ are sustained up to 2 years postoperatively. ${ }^{117}$

Complications of stage I surgery include anaesthesia of the lower lip in most patients, tooth injury, wound infection, and upper airway obstruction in the early postoperative period. Anaesthesia of the cheek, lower lip and chin are also common after stage II procedures. Velopharyngeal insufficiency occurs commonly in those who have had a previous UPPP. Speech difficulties are relatively common and a change in facial appearance is to be anticipated. Convalescence after maxillomandibular advancement is difficult and the average time off work is 10 weeks.

\section{Tongue base surgery}

Various procedures have been developed to remove excess lingual tissue and increase the calibre of the retrolingual oropharynx. These include glossoplasty, laser midline glossectomy, radiofrequency tissue ablation, lingualplasty and 
Box 2 Obstructive sleep apnoea/hypopnoea syndrome: approach to treatment

\section{General}

Assessment of indications for treatment

- Reasons for referral and patient's expectations

- Disease severity

- symptoms (e.g. hypersomnolence)

- co-morbid medical conditions (e.g. systemic hypertension)

- overnight sleep monitoring

- Specific surgically correctible upper airway abnormalities

- Local expertise in specialised treatments (e.g. maxillofacial surgery)

- Availability of long term follow up

\section{Lifestyle modification}

- Weight loss

- Avoidance of alcohol and sedatives

- Smoking cessation

- Sleep hygiene

- Avoidance of supine sleep position

Adjunctive medical therapy

- Relief of nasal obstruction

- Modafinil for residual hypersomnolence?

- Supplemental oxygen in selected patients

Nasal CPAP for:

- all patients who tolerate it

- moderate to severe OSAHS

- significant medical co-morbidities

- severe hypersomnolence

- diagnostic uncertainty

Oral appliance therapy for:

- patients unable or unwilling to use CPAP

- mild to moderate OSAHS if not morbidly obese

- mandibular deficiency?

Corrective upper airway surgery for:

- treatment failures with nasal CPAP and/or oral appliance therapy

- patients with no significant co-morbidities

- clearly defined locus of upper airway obstruction

- emergency control of upper airway patency (i.e. tracheostomy)

tongue base suspension. These are sometimes incorporated into the stage I surgery outlined above. Woodson and colleagues recently reported a randomised controlled trial comparing temperature controlled radiofrequency tissue ablation (TCRFTA) of the tongue and soft palate with sham placebo surgery and nasal CPAP therapy in patients with mild to moderate OSA. ${ }^{118}$ Effects sizes were small to moderate but felt to be clinically important. Compared with baseline, TCRFTA improved reaction time, disease specific quality of life, and subjective sleepiness. CPAP improved quality of life and sleepiness. There were no differences in outcomes between TCRFTA and CPAP. Compared with sham surgery, TCRFTA increased airway volume, reduced apnoea severity, and improved quality of life. The investigators concluded that TRCFTA and CPAP produce comparable improvements in quality of life in patients with mild to moderate OSAHS.

\section{Tracheostomy}

Tracheostomy is the only surgical procedure that is consistently effective in relieving OSAHS. ${ }^{78}{ }^{119}{ }^{120}$ Additional benefits include resolution of chronic hypercapnic respiratory failure and cor pulmonale, and improvements in systemic hypertension and cardiac dysrhythmias. Central apnoeas, probably caused by unstable control of breathing, may persist after tracheostomy, but eventually resolve within 6 months. ${ }^{121}$ The major drawbacks of tracheostomy are the cosmetic effect and its associated psychosocial morbidity. ${ }^{119}$ Granulation tissue formation can cause bleeding and airway obstruction. Postobstructive pulmonary oedema ranging from mild to severe appears to be more common following tracheostomy in patients with OSAHS than in control patients. ${ }^{122}$

\section{APPROACH TO TREATMENT \\ General}

The decision to offer treatment for OSAHS depends on the patient's expectations and the physician's assessment of the severity of the condition in terms of symptoms-particularly hypersomnolence, the presence of co-morbid conditions, and the findings on overnight sleep monitoring. All patients should be counselled to adopt lifestyle modifications such as weight loss, avoidance of alcohol and other sedatives, smoking cessation, and good sleep hygiene that may reduce or eliminate known modifiable risk factors for OSAHS. In addition, patients should be educated about the potential interactions between some of these risk factors and the long term cardiovascular consequences of OSAHS. Measures to minimise the supine sleep posture and relieve chronic nasal obstruction should be routinely recommended. There is currently no role for drug treatment of OSAHS, with the possible exception of modafinil as adjunctive symptomatic relief for patients with persistent hypersomnolence despite nasal CPAP therapy.

\section{Nasal CPAP}

Because of its proven safety, efficacy and reversibility, nasal CPAP is the treatment of choice for patients who have moderate to severe OSAHS, significant medical co-morbidities, hypersomnolence regardless of the degree of abnormality on overnight sleep monitoring, and when there is diagnostic uncertainty. While it is acknowledged to be a cumbersome treatment with variable compliance, every effort should be made to establish such patients on nasal CPAP therapy because of the limited efficacy or invasive nature of the alternatives. Nasal CPAP therapy is dealt with in detail in an earlier article in this series. ${ }^{123}$

\section{Oral appliances}

Oral appliance therapy is a reasonable alternative to nasal CPAP for patients with mild to moderate OSAHS who are not morbidly obese. It may be particularly suitable for patients whose upper airway compromise is mainly attributable to mandibular deficiency. A multidiscipliniary team approach should include a dentist and/or orthodontist who understands the limitations of oral appliance therapy and the implications for dental, orthodontic, and temporomandibular joint function, and should ensure appropriate medical follow up for the patient. 


\section{Upper airway surgery}

Upper airway surgery remains a potentially useful treatment option for certain carefully selected patients with OSAHS. In the absence of data from randomised controlled trials, however, patients should be advised that most of these procedures remain experimental. Accurate diagnosis and follow up assessment using overnight polysomnography is the current standard of care. A multidiscipliniary team approach comprising the respiratory physician or sleep specialist, an otorhinolaryngologist and, in some instances, a maxillofacial surgeon and orthodontist is strongly recommended. Long term follow up is essential because of the uncertainty regarding the long term efficacy of surgical procedures. Careful medical follow up is vitally important to confirm the efficacy of treatment and to offer alternatives when surgical treatment fails, as it often does. Nasal CPAP therapy should be used to stabilise patients with moderate to severe OSAHS preoperatively and to protect against postoperative upper airway obstruction.

Specific obstructing lesions such as adenotonsillar enlargement should be surgically resected. UPPP has been a popular treatment in the past, but earlier enthusiasm has been tempered considerably by the recognition of its limited overall efficacy. UPPP should be restricted to patients with upper airway compromise confined to the velopharynx who are not amenable to other non-invasive treatments. LAUP is not recommended for the treatment of OSAHS. The precise role of maxillofacial surgery remains unclear. Its use should be confined to carefully designed clinical trials performed in centres with expertise in these complex surgical procedures. Maxillofacial surgery may have a role in patients with severe OSAHS and craniofacial dysmorphism who are not amenable to nasal CPAP therapy. Multilevel temperature controlled radiofrequency tissue ablation may be an option for patients with mild to moderate OSAHS. Tracheostomy is rarely required nowadays, but retains a role in the emergency management of severe OSAHS when nasal positive airway pressure therapy is not feasible. The approach to treatment is summarised in box 2 .

\section{REFERENCES}

1 Peker Y, Hedner J, Norum J, et al. Increased incidence of cardiovascular disease in middle-aged men with obstructive sleep apnea. Am J Respir Crit Care Med 2002; 166:159-65.

2 Johns MW. A method for measuring daytime sleepiness: the Epworth sleepiness scale. Sleep 1991;14:540-5.

3 Lam B, Ryan CF. Arnold-Chiari malformation presenting as sleep apnea syndrome. Sleep Med 2000;1:139-44.

4 Lam B, Ryan CF. Craniofacial profile predicts obstructive sleep apnea. Am J Respir Crit Care Med 2002; 165:A407.

5 Sneerson J, Wright J. Lifestyle modification for obstructive sleep apnea. (Cochrane Review) The Cochrane Library. Issue 2. Oxford: Update Software, 2002.

6 Wilcox I, McNamara SG, Collins FL, et al. "Syndrome Z": the interaction of sleep apnea, vascular risk factors and heart disease. Thorax 1998;53:S25-8.

7 Guilleminault C, Van den Hoed J, Mitler M. Clinical overview of the sleep apnea syndromes. In: Guilleminault C, Dement W, eds. Sleep apnea syndromes. New York: Alan R Liss, 1978:1-12.

8 Bliwise D, Feldman D, Bliwise N, et al. Risk factors for sleep disordered breathing in heterogeneous geriatric populations. J Am Geriatr Soc 1987;35:132-41.

9 Grunstein R, Wilcox I, Yang T, et al. Snoring and sleep apnea in men: association with central obesity and hypertension. Int $J$ Obesity 1993; 17:533-40.

10 Rajala R, Partinen M, Sane T, et al. Obstructive sleep apnea syndrome in morbidly obese patients. J Intern Med 1991;230:125-9.

11 Stradling JR, Crosby JH. Predictors and prevalence of obstructive sleep apnea and snoring in 1001 middle-aged men. Thorax 1991;46:85-90.

12 Browman CP, Sampson MG, Yolles SF, et al. Obstructive sleep apnea and body weight. Chest 1984;85:435-6.

13 Harman EM, Wynne JW, Block AJ. The effect of weight loss on sleep disordered breathing and oxygen desaturation in morbidly obese men. Chest 1982;82:291-4.

14 Peiser P, Lavie P, Ovnat A, et al. Sleep apnea syndrome in the morbidly obese as an indication for weight reduction surgery. Ann Surg 1984; 199: 112-5.
15 Kuna S, Remmers JE. Anatomy and physiology of upper airway obstruction. In: Kryger MH, Roth T, Dement WC, eds. Principles and practice of sleep medicine. Philadelphia: W B Saunders, 2000:840-58.

16 Ferguson KA, Ono T, Lowe AA, et al. The relationship between obesity and craniofacial structure in obstructive sleep apnea. Chest 1995;108:375-81.

17 Wittels EH, Thompson S. Obstructive sleep apnea and obesity. Otolaryngol Clin North Am 1986;90:225-37.

18 Travis KA, Barr SI, Fleming JA, et al. Weight gain in obese men with obstructive sleep apnea. J Am Diet Assoc 2002; 102:703-6.

19 Strobel RJ, Rosen RL. Obesity and weight loss in obstructive sleep apnea: a critical review. Sleep 1996; 19:104-15.

20 Bonara M, Shields GI, Knuth SL, et al. Selective depression by ethanol of upper airway respiratory activity in cats. Am Rev Respir Dis 1984; 130:156-61.

21 Krol RC, Knuth SL, Bartlett D Jr. Selective reduction of genoglossus muscle activity by alcohol in normal human subjects. Am Rev Respir Dis 1984; 129:247-50

22 Dawson A, Bigby BG, Poceta S, et al. Effect of bedtime alcohol on inspiratory resistance and respiratory drive in snoring and nonsnoring men. Alcohol Clin Exp Res 1997;21:183-90.

23 Scanlan MF, Roebuck T, Little PJ, et al. Effect of moderate alcohol upon obstructive sleep apnoea. Eur Respir J 2000;16:909-13.

24 Issa FG, Sullivan CE. Alcohol, snoring and sleep apnoea. J Neurol Neurosurg Psychiatry 1982;45:353-9.

25 Taasan VC, Block AJ, Boysen PG, et al. Alcohol increases sleep apnea and oxygen desaturation in asymptomatic men. Am J Med 1981;71:240-5.

26 Dolly FR, Block AJ. Effect of flurazepam on sleep-disordered breathing and nocturnal desaturation in asymptomatic subjects. Am J Med 1982;73:239-43.

27 Rafferty TD, Ruskis A, Sasaki C, et al. Perioperative considerations in the management of tracheostomy for the obstructive sleep apnea patient. Br J Anaesth 1980;52:619-21.

28 Serima L, Broudy M, Nay KN, et al. Increased severity of obstructive sleep apnea after bedtime alcohol ingestion: diagnostic potential and proposed mechanism of action. Sleep 1982;5:318-28.

29 Bloom JW, Kaltenhorn WT, Quan SF, et al. Risk factors in a general population for snoring: importance of cigarette smoking and obesity. Chest 1988;93:678-83.

30 Wetter DW, Young TB, Bidwell TR, et al. Smoking as a risk factor for sleepdisordered breathing. Arch Intern Med 1994;154:2219-24.

31 Guilleminault C, Rosekind M. The arousal threshold: sleep deprivation, sleep fragmentation, and obstructive sleep apnea syndrome. Bull Eur Physiopathol Respir 1981;17:341-9.

32 White DP, Douglas NJ, Pickell CK, et al. Sleep deprivation and the control of breathing. Am Rev Respir Dis 1983;128:984-6.

33 Cooper KR, Phillips BA. Effect of short-term sleep loss on breathing. J Appl Physiol 1982;53:855-8.

34 Leiter JC, Knuth SL, Bartlett D. The effect of sleep deprivation on activity of the genioglossus muscle. Am Rev Respir Dis 1985;132:1242-5.

35 Espinoza M, Thornton AT, Sharp D, et al. Sleep fragmentation and ventilatory response to hypercapnia. Am Rev Respir Dis 1991;144:1121-4.

36 Series F, Roy N, Marc I. Effects of sleep deprivation and sleep fragmentation on upper airway collapsibility in normal subjects. Am J Respir Crit Care Med 1994;150:481-5.

37 Smith PL, Wise RA, Gold AR, et al. Upper airway pressure area relationships in obstructive sleep apnea. J Appl Physiol 1982;53:855-8.

38 Penzel T, Möller M, Becker HF, et al. Effect of sleep position and sleep stage on the collapsibility of the upper airways in patients with sleep apnea. Sleep 2001;24:90-5.

39 Oksenberg A, Silverberg DS, Arous E, et al. Positional vs nonpositional obstructive sleep apnea patients: anthropometric, nocturnal polysomnographic, and multiple sleep latency test data. Chest 1997; 1 12:629-39

40 Oksenberg A, Khamaysi I, Silverberg DS, et al. Association of body position with severity of apneic events in patients with severe nonpositional obstructive sleep apnea. Chest 2000;118:1018-24.

41 Itasaka Y, Miyazaki S, Ishikawa K, et al. The influence of sleep position and obesity on sleep apnea. Psych Clin Neurosci 2000;54:340-1.

42 Berger $M$, Oksenberg A, Silverberg DS, et al. Avoiding the supine position during sleep lowers $24 \mathrm{~h}$ blood pressure in obstructive sleep apnea (OSA) patients. J Human Hypertens 1997; 1 1:657-64.

43 Jokic R, Klimaszewski A, Crossley M, et al. Positional treatment vs continuous positive airway pressure in patients with positional obstructive sleep apnea syndrome. Chest 1999;115:771-81.

44 Taasen V, Wynne JW, Cassisi N, et al. The effect of nasal packing on sleepdisordered breathing and nocturnal oxygen desaturation. Laryngoscope 1981;91:1163-72.

45 Lavie P, Gertner R, Zomer J, et al. Breathing disorders in sleep associated with "microarousals" in patients with allergic rhinitis. Acta Otolaryngol 1981;92:529-33.

46 McNicholas WT, Tarlo S, Cole P, et al. Obstructive apneas during sleep in patients with seasonal allergic rhinitis. Am Rev Respir Dis 1982;126:625-8.

47 Olsen KD, Kern EB, Westbrook PR. Sleep and breathing disturbances secondary to nasal obstruction. Otolaryngol Head Neck Surg 1981;89:804-10.

48 Series F, St. Pierre S, Carrier G. Effects of surgical correction of nasal obstruction in the treatment of obstructive sleep apnea. Am Rev Respir Dis 1992; 146:1261-5

49 Kerr $\mathbf{P}$, Millar T, Buckle $\mathrm{P}$, et al. The importance of nasal resistance in obstructive sleep apnea syndrome. J Otolaryngol 1992;21:189-95. 
50 Friedman $M$, Tanyeri $\mathrm{H}$, Lim JW, et al. Effect of improved nasal breathing on obstructive sleep apnea. Otolaryngol Head Neck Surg 2000;122:71-4.

51 Verse T, Maurer JT, Pirsig W. Effect of nasal surgery on sleep-related breathing disorders. Laryngoscope 2002;112:64-8.

52 Hudgel DW, Thanakitcharu S. Pharmacologic treatment of sleep-disordered breathing. Am J Respir Crit Care Med 1998;158:691-9.

53 Smith I, Lasserson T, Wright J. Drug treatments for obstructive sleep apnea (Cochrane Review). In: The Cochrane Library. Issue 2. Oxford: Update Software, 2002.

54 Cook WR, Benich JJ, Wooten SA. Indices of severity of obstructive sleep apnea syndrome do not change during medroxyprogesterone acetate therapy. Chest 1989;96:262-6.

55 Whyte KF, Gould GA, Airlie MA, et al. Role of protriptyline and acetazolamide in the sleep apnea/hypopnea syndrome. Sleep 1988;11:463-72.

56 Brownell LG, West $P$, Sweatman $P$, et al. Protriptyline in obstructive sleep apnea: a double blind trial. N Engl J Med 1982;307:1037-42

57 Stepanski EJ, Conway WA, Young DK, et al. A double-blind trial of protriptyline in the treatment of sleep apnea syndrome. Henry Ford Hosp Med J 1988;36:5-8.

58 Mulloy E, McNicholas WT. Theophylline in obstructive sleep apnea: adouble-blind evaluation. Chest 1992;101:753-7.

59 Horner RL. Motor control of the pharyngeal musculature and implications for the pathogenesis of obstructive sleep apnea. Sleep 1996;19:827-53.

60 Horner RL. Is there a rationale in modulating brainstem neurons in obstructive sleep apnea and is it clinically relevant? Sleep 2000;23:S179-81.

61 Kingshott RN, Vennelle M, Coleman EL, et al. Randomized, double-blind, placebo-controlled crossover trial of modafinil in the treatment of residual excessive daytime sleepiness in the sleep apnea/hypopnea syndrome. Am J Respir Crit Care Med 2001:103:918-23.

62 Pack Al, Black JE, Schwartz JRL, et al. Modafinil as adjunct therapy for daytime sleepiness in obstructive sleep apnea. Am J Respir Crit Care Med 2001; 164:1675-81.

63 Bradley TD, Phillipson EA. Pathogenesis and pathophysiology of obstructive sleep apnea syndrome. Med Clin North Am 1985;69:1 169-85.

64 Sajkov D, Wang T, Saunders NA, et al. Daytime pulmonary hemodynamics in patients with obstructive sleep apnea without lung disease. Am J Respir Crit Care Med 1999:159:1518-26.

65 Guilleminault C, Connolly S, Winkle RA. Cardiac arrhythmia and conduction disturbances during sleep in 400 patients with sleep apnea syndrome. Am J Cardiol 1983;52:490-4.

66 Findley U, Barth JT, Powers DC, et al. Cognitive impairment in patients with obstructive sleep apnea and associated hypoxemia. Chest 1986;90:686-90.

67 Martin RJ, Sanders MH, Gray BA, et al. Acute and long-term ventilatory effects of hyperoxia in the adult sleep apnea syndrome. Am Rev Respir Dis 1982; 125:175-80.

68 Gold AR, Schwartz AR, Bleecker ER, et al. The effect of chronic nocturnal oxygen administration upon sleep apnea. Am Rev Respir Dis 1986;134:925-9.

69 Hensley MJ, Read DJ. Intermittent obstruction of the upper airway during sleep causing profound hypoxemia: a neglected mechanism exacerbating chronic respiratory failure. Aust NZ J Med 1976;6:481-6.

70 Schonhofer B, Franklin KA, Brunig H, et al. Effect of nasal-valve dilation on obstructive sleep apnea. Chest 2000;118:587-90.

71 Nahmias JS, Karetzky MS. Treatment of the obstructive sleep apnea syndrome using a nasopharyngeal tube. Chest 1988;94:1142-7.

72 Jocik R, Klimaszewski A, Mink J, et al. Surface tension forces in sleep apnea the role of a soft tissue lubricant: a randomized controlled trial. Am J Respir Crit Care Med 1998;157:1522-55.

73 Schwartz AR, Bennett ML, Smith PL, et al. Therapeutic electrical stimulation of the hypoglossal nerve in obstructive sleep apnea. Arch Otolaryngol Head Neck Surg 2001;127:1216-23.

74 Schneider H, O'Hearn DJ, Leblanc K, et al. High-flow transtracheal insufflation treats obstructive sleep apnea: a pilot study. Am J Respir Crit Care Med 2000;161:1869-76.

75 Garrigue C, Bordier P, Jais P, et al. Benefit of atrial pacing in sleep apnea syndrome. N Engl J Med 2002;346:404-12.

76 Meoli AM, Rosen CL, Kristo D, et al. Nonprescription treatments of snoring or obstructive sleep apnea: an evaluation of products with limited scientific evidence. Sleep 2003;26:619-24.

77 Motta J, Guilleminault HC, Schroeder JS, et al. Tracheostomy and hemodynamic changes in sleep-induced apnea. Ann Intern Med 1978:89:454-8.

78 Guilleminault HC, Simmons FB, Motta J, et al. Obstructive sleep apnea syndrome and tracheostomy: longterm follow-up experience. Arch Intern Med 1981;141:985-8.

79 Snider GL. Health-care technology assessment of surgical procedures. The case of reduction pneumoplasty for emphysema. Am J Respir Crit Care Med 1996;153:1208-13.

80 Bridgman SA, Dunn KM, Ducharme F. Surgery for obstructive sleep apnea (Cochrane Review). In: The Cochrane Library. Issue 2. Oxford: Update Software, 2000.

81 Standards of Practice Committee of the American Sleep Disorders Association. Practice parameters for the treatment of obstructive sleep apnea in adults: the efficacy of surgical modifications of the upper airway. Sleep 1996; 19:152-5.

82 Sher AE, Schechtman KB, Piccirillo JF. The efficacy of surgical modifications of the upper airway in adults with obstructive sleep apnea syndrome. Sleep 1996;19:156-77.
83 Sackett DL. Rules of evidence and clinical recommendations on the use of antithrombotic agents. Arch Intern Med 1986;146:464-5.

84 Rojeweski T, Schuller D, Clark R, et al. Videoendoscopic determination of the mechanism of obstruction in obstructive sleep apnea. Otolaryngol Head Neck Surg 1984:92:127-31.

85 Sher A. Obstructive sleep apnea syndrome: a complex disorder of the upper airway. Otolaryngol Head Neck Surg 1990;23:593-608.

86 Morrison DL, Launois SH, Isono S, et al. Pharyngeal narrowing and closing pressures in patients with obstructive sleep apnea. Am Rev Respir Dis 1993:148:606-11.

87 Hudgel DW. Variable site of airway narrowing among obstructive sleep apnea patients. J Appl Physiol 1986;61:1403-9.

88 Shepard JW Jr, Thawley SE. Evaluation of the upper airway by computerized tomography in patients undergoing uvulopalatopharyngoplasty for obstructive sleep apnea. Am Rev Respir Dis 1989;140:711-6.

89 Launois SH, Feroah TR, Campbell WN, et al. Site of pharyngeal narrowing predicts outcome of surgery for obstructive sleep apnea. Am Rev Respir Dis 1993; 147:71-94.

90 Ryan CF, Dickson Rl, Lowe AA, et al. Upper airway measurements predict response to uvulopalatopharyngoplasty in obstructive sleep apnea. Laryngoscope 1990;144:939-44.

91 Ryan CF, Lowe AA, Li D, et al. Three-dimensional upper airway computed tomography in obstructive sleep apnea: a prospective study in patients treated by uvulopalatopharyngoplasty. Am Rev Respir Dis 1991;144:428-32.

92 Sher AE, Thorpy MJ, Shprintzen RJ, et al. Predictive value of Müller maneuver in selection of patients for uvulopalatopharyngoplasty. Laryngoscope 1985;95:1483-7.

93 Schechter MS. Technical report: diagnosis and management of childhood obstructive sleep apnea. Pediatrics 2002;109:e69.

94 Verse T, Kroker BA, Pirsig W, et al. Tonsillectomy as a treatment of obstructive sleep apnea in adults with tonsillar hypertrophy. Laryngoscope 2000;110:1556-9.

95 Fujita S, Conway W, Zorick F, et al. Surgical correction of anatomic abnormalities in obstructive sleep apnea syndrome: uvulopalatopharyngoplasty. Otolaryngol Head Neck Surg 1981;89:923-34.

96 Larsson LH, Carlsson-Nordlander B, Svanborg E. Four-year follow-up after uvulopalatopharyngoplasty in 50 unselected patients with obstructive sleep apnea syndrome. Laryngoscope 1994;104:1362-8.

97 Zohar Y, Finkelstein Y, Talmi YP, et al. Uvulopalatopharyngoplasty: evaluation of postoperative complications, sequelae, and results. Laryngoscope 1991;101:775-9

98 Esclamado RM, Glenn MG, McCulloch TM, et al. Perioperative complications and risk factors in the surgical treatment of obstructive sleep apnea syndrome. Laryngoscope 1989;99:1125-9.

99 Langin T, Pepin J-L, Pendlebury S, et al. Upper airway changes in snorers and mild sleep apnea sufferers after uvulopalatopharyngoplasty (UPPP) Chest 1998;113:1595-603.

100 Dickson RI, Mintz DR. One-stage laser assisted uvulopalatoplasty. J Otolaryngol 1996;25:155-61.

101 Kamami YV. Laser $\mathrm{CO}_{2}$ for snoring: preliminary results. Acta Otorhinolaryngol Belg 1990;44:451-6.

102 Ryan CF. Laser-assisted uvulopalatoplasty in sleep-disordered breathing Thorax 1997:52:5-8.

103 Littner M, Kushida CA, Hartse K, et al. Practice parameters for the use of laser-assisted uvulopalatoplasty: an update for 2000. Sleep 2001;24:603-19.

104 Finkelstein Y, Shapiro-Feinberg M, Stein G, et al. Uvulopalatopharyngoplasty vs laser-assisted uvulopalatoplasty. Arch Otolaryngol Head Neck Surg 1997; 123:265-76.

105 Berger G, Finkelstein Y, Ophir D. Histopathologic changes of the soft palate after laser-assisted uvulopalatoplasty. Arch Otolaryngol Head Neck Surg 1999;125:786-90

106 Berger G, Stein G, Ophir D, Finkelstein Y. Is there a better way to do laserassisted uvulopalatoplasty? Arch Otolaryngol Head Neck Surg 2003;129:447-53.

107 Ferguson KA, Heighway K, Ruby RR. A randomized trial of laser-assisted uvulopalatoplasty in the treatment of mild obstructive sleep apnea. Am J Respir Crit Care Med 2003;167:15-9.

108 Terris DJ, Clarke AA, Norbash AM, et al. Characterization of post-operative edema following laser-assisted uvulopalatoplasty using MRI and polysomnography: implications for the outpatient treatment of obstructive sleep apnea syndrome. Laryngoscope 1996;106:124-8.

109 Ellis PD, Williams JEF, Shneerson JM. Surgical relief of snoring due to palatal flutter: a preliminary report. Ann R Coll Surg 1993;75:286-90

110 Wassmuth Z, Mair E, Loube D, et al. Cautery-assisted palatal stiffening for the treatment of obstructive sleep apnea syndrome. Otolaryngol Head Neck Surg 2000;123:55-60.

111 Stuck B, Maurer JT, Hein G, Hörmann K, Verse T. Radiofrequency surgery of the soft palate in the treatment of snoring: a review of the literature. Sleep 2004;27:551-5

112 Riley RW, Powell NB, Guilleminault C. Obstructive sleep apnea syndrome: a review of 306 consecutively treated surgical patients. Otolaryngol Head Neck Surg 1993;102:117-25.

113 Waite PD, Wooten V, Lachner J, et al. Maxillomandibular advancement surgery in 23 patients with obstructive sleep apnea syndrome. J Oral Maxillofac Surg 1989;47:1256-61.

114 Hochban W, Conradt V, Brandenburg J, et al. Surgical maxillofacial treatment of obstructive sleep apnea. Plast Reconstr Surg 1997;99:619-28. 
115 Prinsell JR. Maxillomandibular advancement surgery in a site-specific treatment approach for obstructive sleep apnea in 50 consecutive patients. Chest 1999;116:1519-29.

116 Bettega CT, Pepin J-L, Veale D, et al. Obstructive sleep apnea syndrome: fifty-one consecutive patients treated by maxillofacial surgery. Am J Respir Crit Care Med 2000;162:641-9.

117 Conradt R, Hochlan W, Brandenburg V, et al. Long-term follow-up of the surgical treatment of obstructive sleep apnea by maxillomandibular advancement. Eur Respir J 1997;10:123-8.

118 Woodson BT, Steward DL, Weaver EM, et al. A randomized trial of temperature-controlled radiofrequency, continuous positive airway pressure and placebo for obstructive sleep apnea syndrome. Otolaryngol Head Neck Surg 2003;128:848-61.
119 Weitzman ED, Kahn E, Pollak CP. Quantitative analysis of sleep apnea before and after tracheostomy in patients with the hypersomnia-sleep apnea syndrome. Sleep 1980;3:407-23.

120 Conway WA, Victor LD, Magilligan DJ Jr, et al. Adverse effects of tracheostomy for sleep apnea. JAMA 1981;246:347-50.

121 Guilleminault C, Cummiskey J. Progressive improvement of apnea index and ventilatory response to $\mathrm{CO}_{2}$ after tracheostomy in obstructive sleep apnea syndrome. Am Rev Respir Dis 1982;126:14-20.

122 Burke AJ, Duke SG, Clyne S, et al. Incidence of pulmonary edema after tracheostomy for obstructive sleep apnea. Otolaryngol Head Neck Surg 2001;125:319-23.

123 Gordon P, Sanders MH. Sleep - 7: Positive airway pressure therapy for obstructive sleep apnoea/hypopnoea syndrome. Thorax 2005;60:74-81.

\section{bmjupdates+}

bmjupdates+ is a unique and free alerting service, designed to keep you up to date with the medical literature that is truly important to your practice.

bmjupdates+ will alert you to important new research and will provide you with the best new evidence concerning important advances in health care, tailored to your medical interests and time demands.

Where does the information come from?

bmjupdates+ applies an expert critical appraisal filter to over 100 top medical journals A panel of over 2000 physicians find the few 'must read' studies for each area of clinical interest

Sign up to receive your tailored email alerts, searching access and more...

www.bmjupdates.com 